\title{
Frontal lobes white matter abnormalities mimicking cystic leukodystrophy in Wilson's disease
}

\section{Anormalidades na substância branca frontal mimetizando leucodistrofia cística na doença de Wilson}

Flavio Moura Rezende Filho', Eva Rocha', Livia Almeida Dutra', José Luiz Pedroso', Orlando G. P. Barsottini

An 18-year-old male presented with a three-year history of slurred speech, gait impairment, seizures and progressive neurological deterioration. Brain MRI depicted bilateral hyperintense T2-signal in the basal ganglia and white matter abnormalities with a cystic appearance in the frontal lobes. Ophthalmological evaluation disclosed KayserFleisher rings (Figure). Ceruloplasmin was low and urinary copper was increased, and Wilson's disease was diagnosed.
Wilson's disease is an autosomal recessive disorder. Typical neurological features include akinetic-rigid syndrome, tremor, ataxia and dystonia ${ }^{1,2}$. Neuroimaging usually shows signal abnormalities in the globus pallidus, putamen, caudate nucleus, thalamus and cerebral peduncles ${ }^{1,2}$. Frontal white matter involvement mimicking leukodystrophy with cystic evolution is a rare presentation ${ }^{3,4}$.

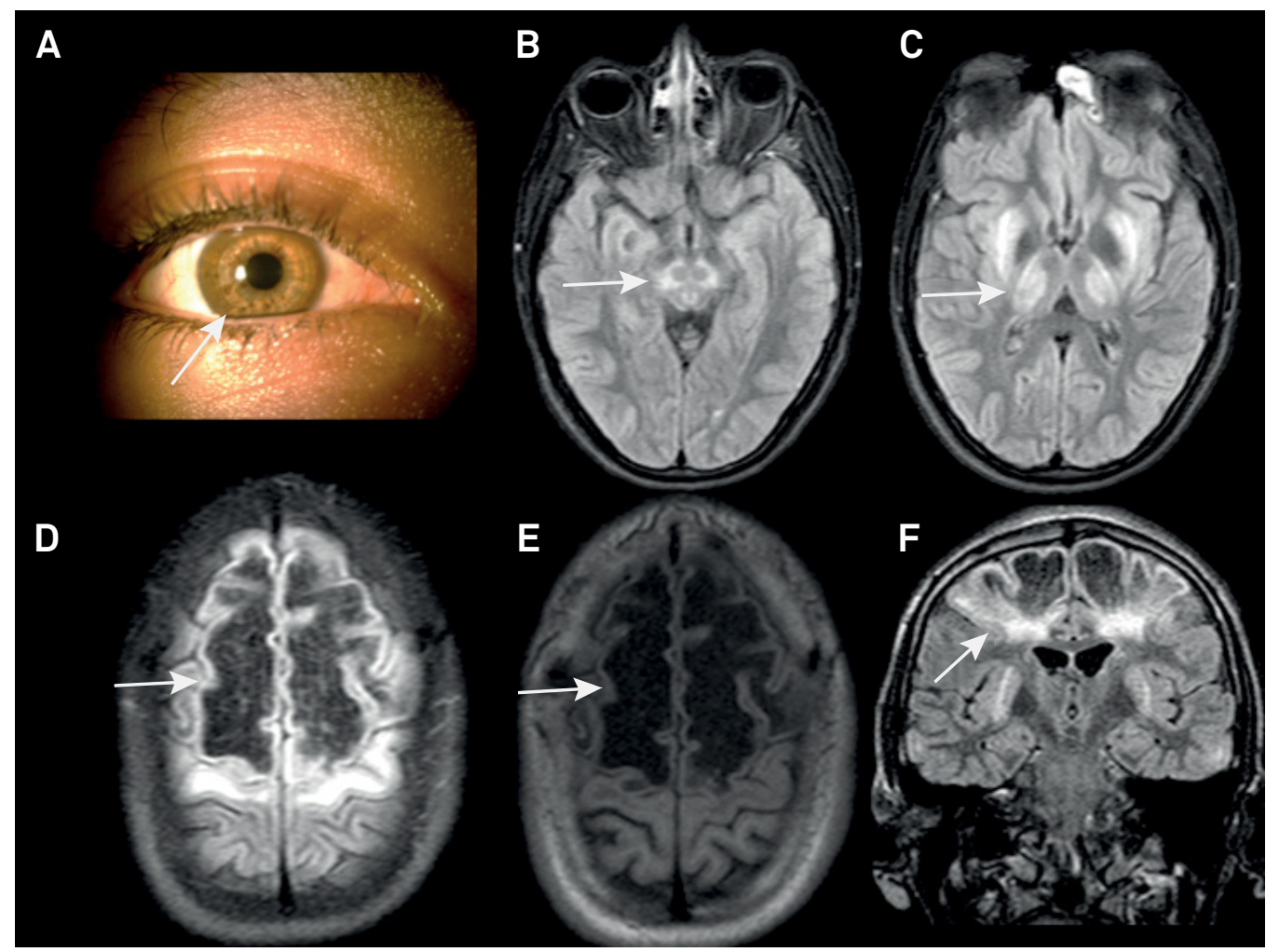

Figure. A. Kayser-Fleischer ring (arrow). B and C: Axial FLAIR-weighted brain MRI shows a giant Panda sign and hyperintense signs in the basal ganglia. D, E and F: marked bilateral frontal leukoencephalopathy with cystic lesions.

${ }^{1}$ Universidade Federal de São Paulo, Departamento de Neurologia e Neurocirurgia, Divisão de Neurologia Geral, São Paulo SP, Brasil.

Correspondence: Orlando Barsottini; Departamento de Neurologia e Neurocirurgia, UNIFESP; Rua Napoleão de Barros, 715; $04023-900$ São Paulo SP, Brasil; E-mail: orlandobarsottini@gmail.com

Conflict of interest: There is no conflict of interest to declare.

Received 05 July 2016; Accepted 08 November 2016. 


\section{References}

1. Bandmann O, Weiss KH, Kaler SG. Wilson's disease and other neurological copper disorders. Lancet Neurol. 2015;14(1):103-13. https://doi.org/10.1016/S1474-4422(14)70190-5

2. Machado A, Chien HF, Deguti MM, Cançado E, Azevedo RS, Scaff M et al. Neurological manifestations in Wilson's disease: report of 119 cases. Mov Disord. 2006;21(12):2192-6. https://doi.org/10.1002/mds.21170
3. Hedera P, Brewer GJ, Fink JK.. White matter changes in Wilson disease. Arch Neurol. 2002;59(5):866-7.

4. Trocello JM, Woimant F, El Balkhi S, Guichard JP, Poupon J, Chappuis P, Feillet F. Extensive striatal, cortical, and white matter brain MRI abnormalities in Wilson disease. Neurology. 2013;81(17):1557. https://doi.org/10.1212/WNL.0b013e3182a95883 